\title{
Clinicopathological features and prognostic analysis of metastatic pulmonary sarcomatoid carcinoma: a SEER analysis
}

\author{
Congjia Xiao $^{1,2}$, Xudong Yang ${ }^{1,2}$, Jianqi $\mathrm{Hao}^{2}$, Chenglin Guo ${ }^{1,2}$, Qiang Pu ${ }^{1,2}$, Lunxu Liu ${ }^{1,2,3}$ \\ ${ }^{1}$ Department of Thoracic Surgery, West China Hospital, Sichuan University, Chengdu, China; ${ }^{2}$ West China School of Medicine, Sichuan University, \\ Chengdu, China; ${ }^{3}$ Western China Collaborative Innovation Center for Early Diagnosis and Multidisciplinary Therapy of Lung Cancer, Sichuan \\ University, Chengdu, China \\ Contributions: (I) Conception and design: C Xiao, X Yang; (II) Administrative support: L Liu; (III) Provision of study materials or patients: X Yang; \\ (IV) Collection and assembly of data: C Xiao, X Yang, J Hao; (V) Data analysis and interpretation: C Xiao; (VI) Manuscript writing: All authors; (VII) \\ Final approval of manuscript: All authors. \\ Correspondence to: Lunxu Liu. Department of Thoracic Surgery, West China Hospital, Sichuan University, Chengdu, China. \\ Email: lunxu_liu@aliyun.com.
}

Background: Pulmonary sarcomatoid carcinoma (PSC) is a rare type of non-small cell lung cancer (NSCLC). Metastases are often detected at the first diagnosis. Despite high rates of distant metastasis, there is insufficient data describing the characteristics of PSC metastasis.

Methods: We performed a Surveillance, Epidemiology, and End Results (SEER) database-based analysis of clinicopathological features and prognosis of distant metastasis in PSC patients. Data queried for this analysis included PSC patients in the database between 2010 and 2016.

Results: A total of 934 patients met the criteria for inclusion in the analysis and included, at the time of diagnosis, $512(54.8 \%)$ patients with metastasis, including bone $(\mathrm{n}=152 ; 16.3 \%)$, brain $(\mathrm{n}=108 ; 11.6 \%)$, liver ( $\mathrm{n}=70 ; 7.5 \%)$, lung $(\mathrm{n}=142 ; 15.2 \%)$ metastases. Binary logistic regression showed that patients with giant cell carcinoma [odds ratio (OR) 4.023, 95\% confidence interval (CI): 2.113-7.661, $\mathrm{P}<0.001$ ] and spindle cell carcinoma (OR 3.151, 95\% CI: 1.699-5.843, $\mathrm{P}<0.001$ ) were associated with metastasis. Log-rank test and Kaplan-Meier plots indicated poor prognosis in metastatic patients [the 1-, 3-, and 5-year overall survival (OS) rates were $14.1 \%, 5.5 \%$, and $4.8 \%$, respectively]. Multivariable analysis showed younger and chemotherapy as improved prognostic factors of PSC patients with single metastasis site.

Conclusions: The SEER database-based analysis revealed the clinical features of distant metastasis of PSC and showed that different histological types posed distinct metastasis potential. Besides, age and chemotherapy were the independent prognostic factors of PSC patients with single metastasis site.

Keywords: Metastasis; pulmonary sarcomatoid carcinoma (PSC); prognosis; Surveillance, Epidemiology, and End Results (SEER) database; treatment

Submitted Sep 04, 2020. Accepted for publication Nov 20, 2020.

doi: $10.21037 /$ jtd-20-2826

View this article at: http://dx.doi.org/10.21037/jtd-20-2826

\section{Introduction}

Lung cancer is the leading cause of death among cancer patients, with non-small cell lung cancer (NSCLC) accounting for $80-85 \%$ of the cases (1). However, pulmonary sarcomatoid carcinoma (PSC), a rare type of NSCLC, that has been estimated to represent less than $1 \%$ of all lung cancer (2-4), exhibits a high degree of malignancy and comprises nearly half of distant metastasis (5-8), and poor prognosis (8-11). Further, PSC is common among older men and smokers $(7,12)$. Although clinical features of PSC and imaging examination have certain characteristics, additional pathological and immunohistochemical examinations are required for accurate diagnosis (13). Nevertheless, there have been few 
previous reports in the literature describing the distribution and characteristics of PSC metastasis, despite high rate of distant metastasis, prompting the need for additional analyses. The Surveillance, Epidemiology, and End Results (SEER) database of survival data from populationbased cancer registries encompass 35\% of the American population. The SEER database documented data on PSC since 1975 and PSC metastasis sites in bone, brain, liver, and lung since 2010. The aim of the current study was to analyze the characteristics of metastatic PSC patients using SEER analysis.

We present the following article in accordance with the STROBE reporting checklist (available at http://dx.doi. org/10.21037/jtd-20-2826).

\section{Methods}

\section{Patients}

This database study used SEER-18 Dataset consisting of 18 cancer registries across the United States. Patients with PSC diagnosed between 2010 and 2016 were included in this study. Data were extracted using the SEER*Stat software (version 8.3.6) of the National Cancer Institute. Diagnosed cases were identified by the specific codes of the International Classification of Diseases for Oncology, $3^{\text {rd }}$ edition (ICD-O) under which pleomorphic carcinoma (8022/3), spindle cell carcinoma (8032/3), giant cell carcinoma (8031/3), carcinosarcoma (8980/3) and pulmonary blastoma (8972/3) are grouped under the term PSC (9). Variables including sex, age of diagnosis, race, primary lesion, tumor size, stage, metastatic site, histological type, differentiation grade, marital status, surgery, radiotherapy, chemotherapy, survival time, and vital status were extracted from the SEER database. We categorized the age of diagnosis ( $\geq 60$ or $>60$ years old), metastasis stage (metastasis or non-metastasis), marital status (married or single), and coded tumor size (T1-2 or T3-4).

\section{Statistical analysis}

Demographic and tumor characteristics were summarized with descriptive statistics. Comparisons of categorical variables were performed using the Chi square and Fisher's exact probability test. The metastasis correlation factors were compared by binary logistics regression analysis showing odds ratio (OR) and 95\% confidence intervals (CI). For overall survival (OS), univariate associations of all cohorts were evaluated using the Cox proportional hazard model and log-rank test. Log-rank P values and KaplanMeier plots were used to compare the survival difference of variables. When calculating the OS rate, the value of missing time point was replaced by the previous nondeleted time point survival rate. Cox proportional hazards model was used for identifying risk factors of prognosis with single-site metastasis patients and included univariate and multivariate analyses, with hazard ratio (HR) and 95\% CI. All statistical analyses were performed using SPSS version 23.0 (IBM Inc. Chicago, IL, USA). A two-sided P value less than 0.05 was considered as statistically significant.

\section{Ethics}

The study was conducted in accordance with the Declaration of Helsinki (as revised in 2013). This was an open database study that involved no identifiable information for individuals throughout the analysis, and therefore, Institutional Review Board of the Disciplines of Excellence and West China Hospital, Sichuan University (ZYGD18021) (1.3.5 Project) consent for this database analysis was waived.

\section{Results}

A total of 3,665 cases of PSC, diagnosed between 1975 and 2016, were identified in the SEER database. The absence of metastatic sites data prior to 2010 in the SEER database resulted in the exclusion of 2,705 patients, and 26 patients were further excluded due to missing and inconsistent data on metastasis status. Finally, 934 cases were considered for final analysis (Figure 1).

Demographic analysis revealed a higher number of males ( $\mathrm{n}=551 ; 59.0 \%)$ compared to females $(\mathrm{n}=383 ; 41.0 \%)$, showing a 1.5:1 distribution. The mean and median age for the whole group were $68.9 \pm 11.5$ and $70 \pm 17$ years, respectively. The population was distributed into 512 $(54.8 \%)$ cases of metastatic disease and $422(45.2 \%)$ cases of non-metastatic disease and a between-group comparison of the clinical features is shown in Table 1. Data on distant lymph node or other site metastases were missing and therefore, not included. The common metastatic sites included bone ( $\mathrm{n}=152,16.3 \%)$, brain $(\mathrm{n}=108,11.6 \%)$, liver ( $\mathrm{n}=70,7.5 \%)$, and lung $(\mathrm{n}=142,15.2 \%)$. Clinicopathological features of patients with different sites of distant metastases are listed in Table 2.

Univariate analysis showed that a significantly higher 


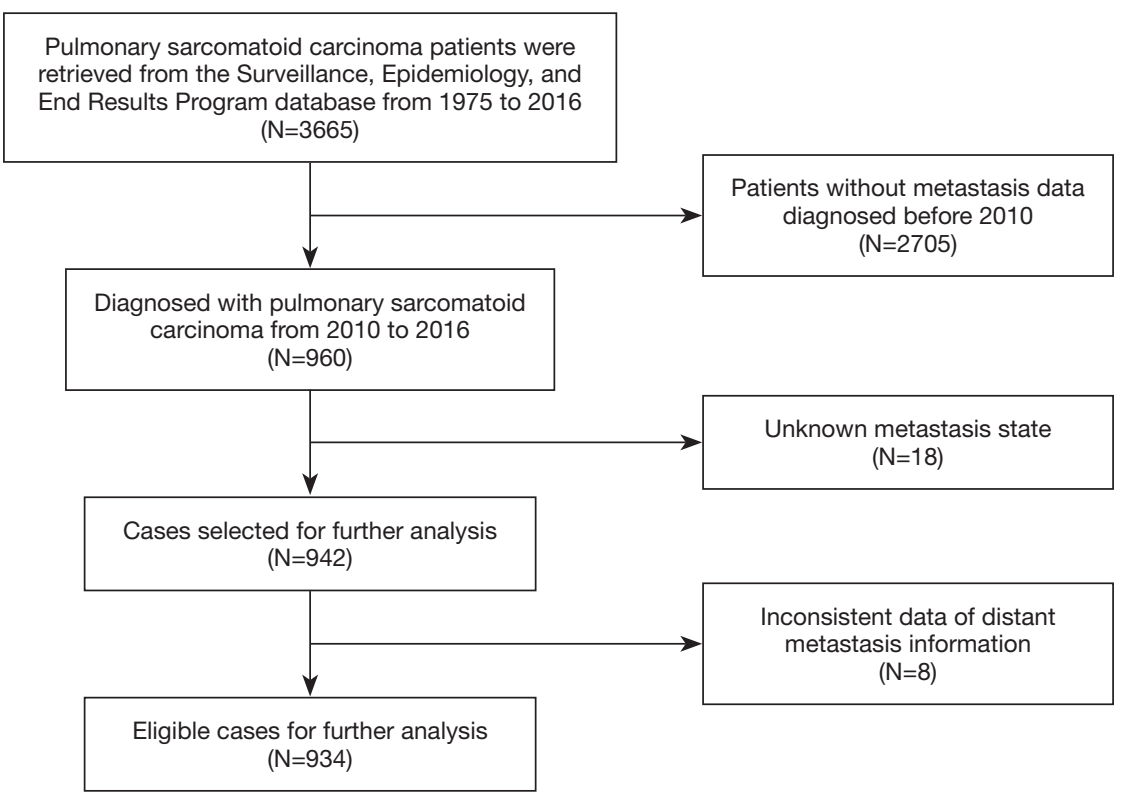

Figure 1 Data disposition.

Table 1 Comparison of clinicopathological characteristics between non-metastasis and metastasis PSC patients of the overall cohort

\begin{tabular}{|c|c|c|c|}
\hline Variable & Non-metastasis, N (\%) & Metastasis, $\mathrm{N}(\%)$ & $P$ value \\
\hline Male & $236(55.9)$ & $315(61.5)$ & \\
\hline Female & $186(44.1)$ & $197(38.5)$ & \\
\hline Age & & & 0.474 \\
\hline$>60$ years & $329(78.0)$ & $389(76.0)$ & \\
\hline Race & & & 0.023 \\
\hline Other (American Indian/AK Native, Asian/Pacific Islander) & $22(5.2)$ & $31(6.1)$ & \\
\hline White & $357(84.8)$ & $400(78.1)$ & \\
\hline Upper lobe, lung & $246(61.2)$ & $244(58.4)$ & \\
\hline Middle lobe, lung & $20(5.0)$ & $24(5.7)$ & \\
\hline Lower lobe, lung & $116(28.9)$ & $130(31.1)$ & \\
\hline Overlapping lesion of lung & $8(2.0)$ & $4(1.0)$ & \\
\hline Tumor size & & & 0.030 \\
\hline T1-2 & $162(50.2)$ & 149 (41.9) & \\
\hline T3-4 & $161(49.8)$ & 207 (58.1) & \\
\hline
\end{tabular}

Table 1 (continued) 
Table 1 (continued)

\begin{tabular}{|c|c|c|c|}
\hline Variable & Non-metastasis, N (\%) & Metastasis, $\mathrm{N}(\%)$ & $P$ value \\
\hline Pleomorphic carcinoma & $171(40.5)$ & $131(25.6)$ & \\
\hline Giant cell carcinoma & $43(10.2)$ & $110(21.5)$ & \\
\hline Spindle cell carcinoma, NOS & $103(24.4)$ & $175(34.2)$ & \\
\hline Carcinosarcoma, NOS & $87(20.6)$ & $91(17.8)$ & \\
\hline Grade & & & 0.278 \\
\hline Well differentiated or moderately differentiated & $7(2.5)$ & $2(0.9)$ & \\
\hline Poorly differentiated & $203(73.6)$ & $159(71.3)$ & \\
\hline Married & $217(54.3)$ & $283(58.1)$ & \\
\hline Single & $183(45.8)$ & 204 (41.9) & \\
\hline Surgery & & & $<0.001$ \\
\hline No & $137(32.7)$ & $457(89.6)$ & \\
\hline Yes & $282(67.3)$ & $53(10.4)$ & \\
\hline Radiation & & & $<0.001$ \\
\hline None/unknown & 309 (73.2) & $299(58.4)$ & \\
\hline Yes & $113(26.8)$ & 213 (41.6) & \\
\hline
\end{tabular}

PSC, pulmonary sarcomatoid carcinoma.

proportion of PSC patients were of the white race than that of black/African American and other races $(\mathrm{P}=0.023)$ in both metastasis and non-metastasis groups (Table 1). Significantly higher number of large tumors (T3-4) were noted in the metastatic group $(\mathrm{P}=0.030)$. For histological types, the proportions of pleomorphic carcinoma patients in the non-metastasis group and spindle cell carcinoma patients in the metastasis group were significantly more than the other types $(\mathrm{P}<0.001)$. While the number of metastatic PSC patients who received surgical treatment was small $(\mathrm{P}<0.001)$, the proportion who received radiotherapy in the metastasis group was significantly higher compared to non-metastatic patients $(\mathrm{P}<0.001)$. The analysis of different metastatic sites (Table 2) showed a significant reduction in the number of patients without surgery for bone $(\mathrm{P}=0.001)$ or lung $(\mathrm{P}=0.010)$ metastases. The proportion of patients with bone $(\mathrm{P}=0.002)$ or brain $(\mathrm{P}<0.001)$ metastases receiving radiotherapy was significantly higher than those who did not have radiotherapy. The proportions of patients with brain metastases who were younger than 60 years of age $(\mathrm{P}<0.001)$, and those with pleomorphic carcinoma and giant cell carcinoma $(\mathrm{P}=0.001)$ were higher compared to patients without brain metastases. In addition, the proportion of white patients with lung metastases was significantly higher than that of other races $(\mathrm{P}=0.024)$.

Risk factors associated with metastasis were analyzed by binary logistics regression, which showed that patients with giant cell carcinoma (OR 4.023, 95\% CI: 2.113-7.661, $\mathrm{P}<0.001)$ and spindle cell carcinoma (OR 3.151, 95\% CI: 1.699-5.843, $\mathrm{P}<0.001$ ) (Table 3) were more significantly 


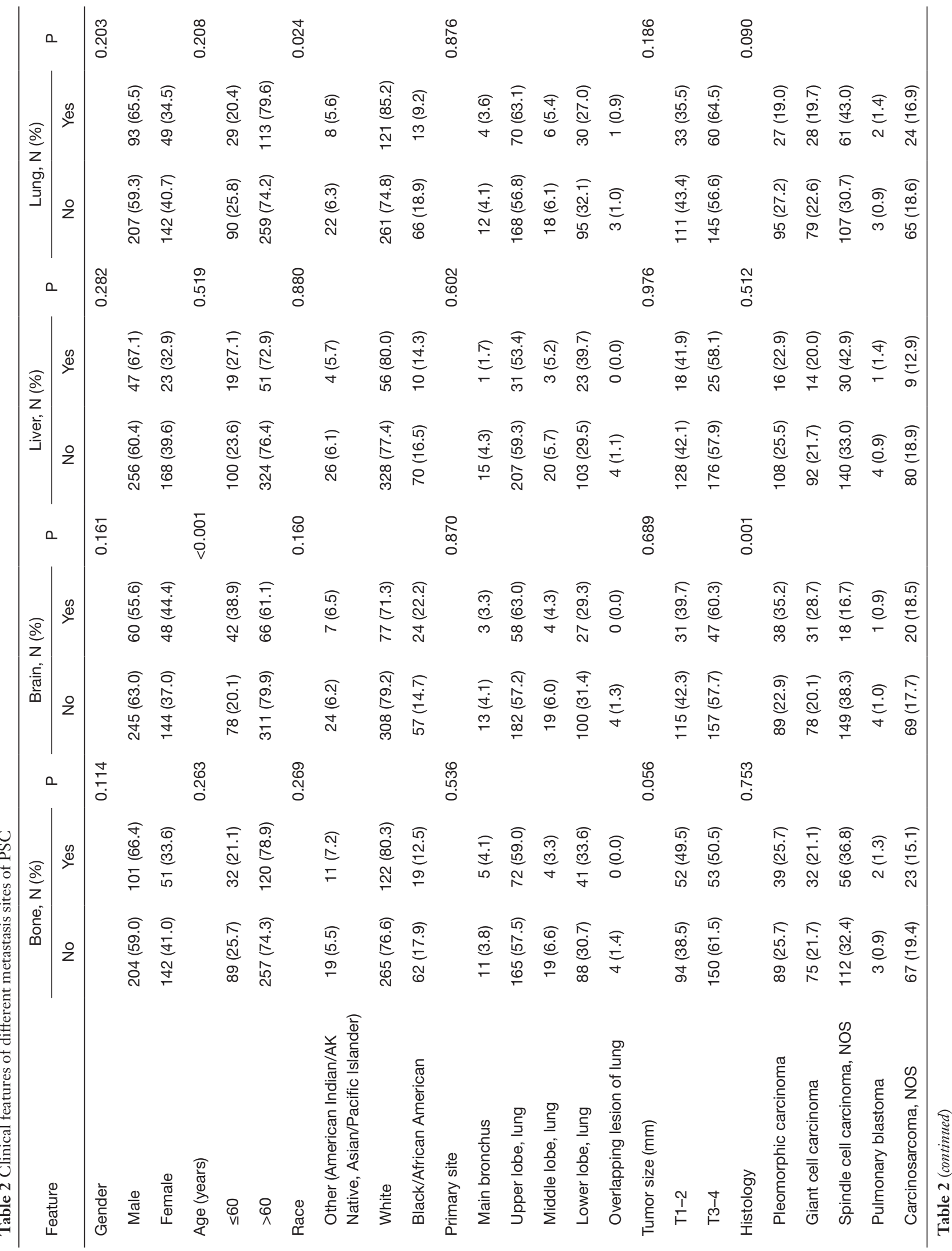




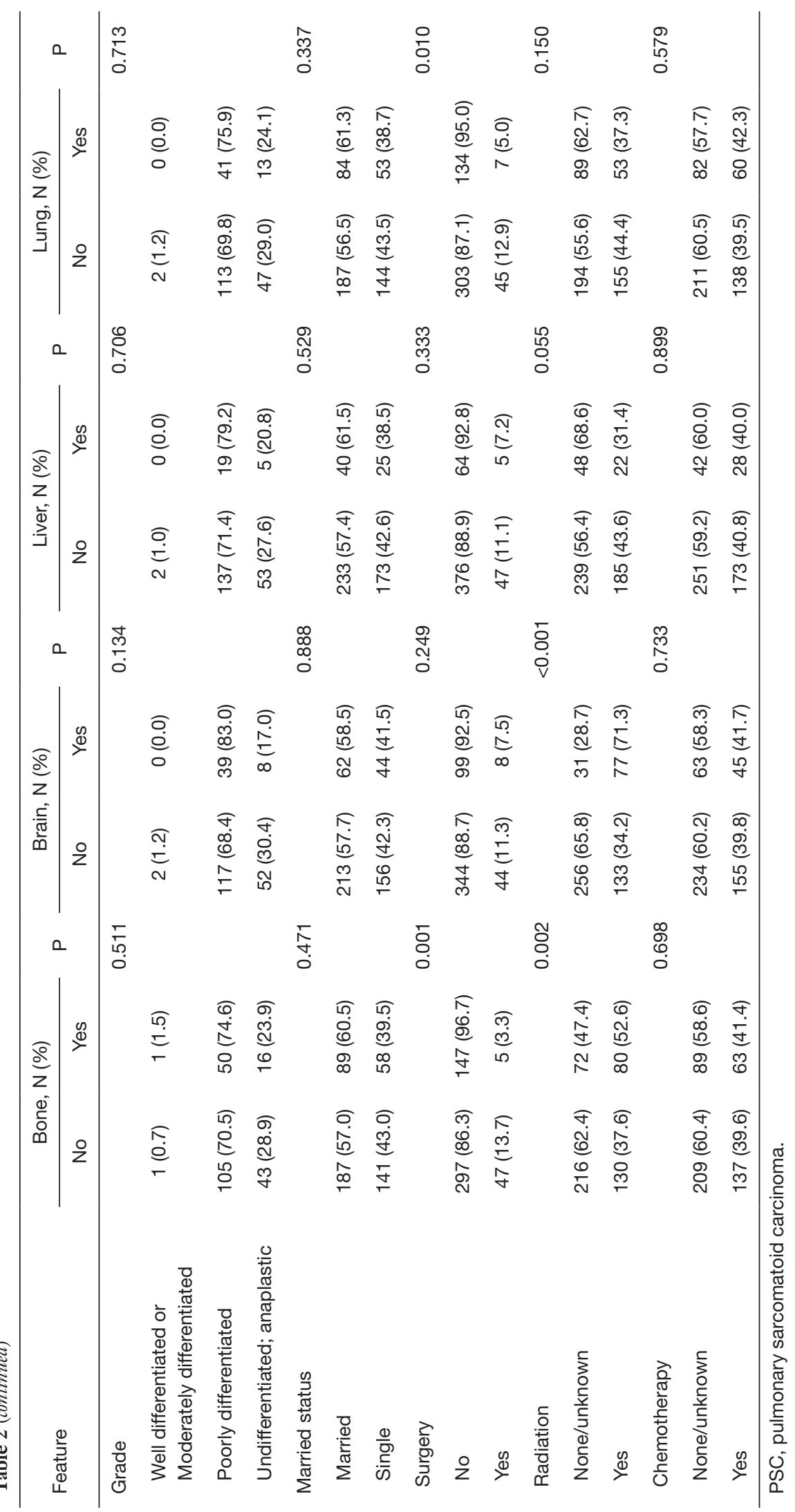


Table 3 Binary logistic regression of factors associated with distant metastases in PSC

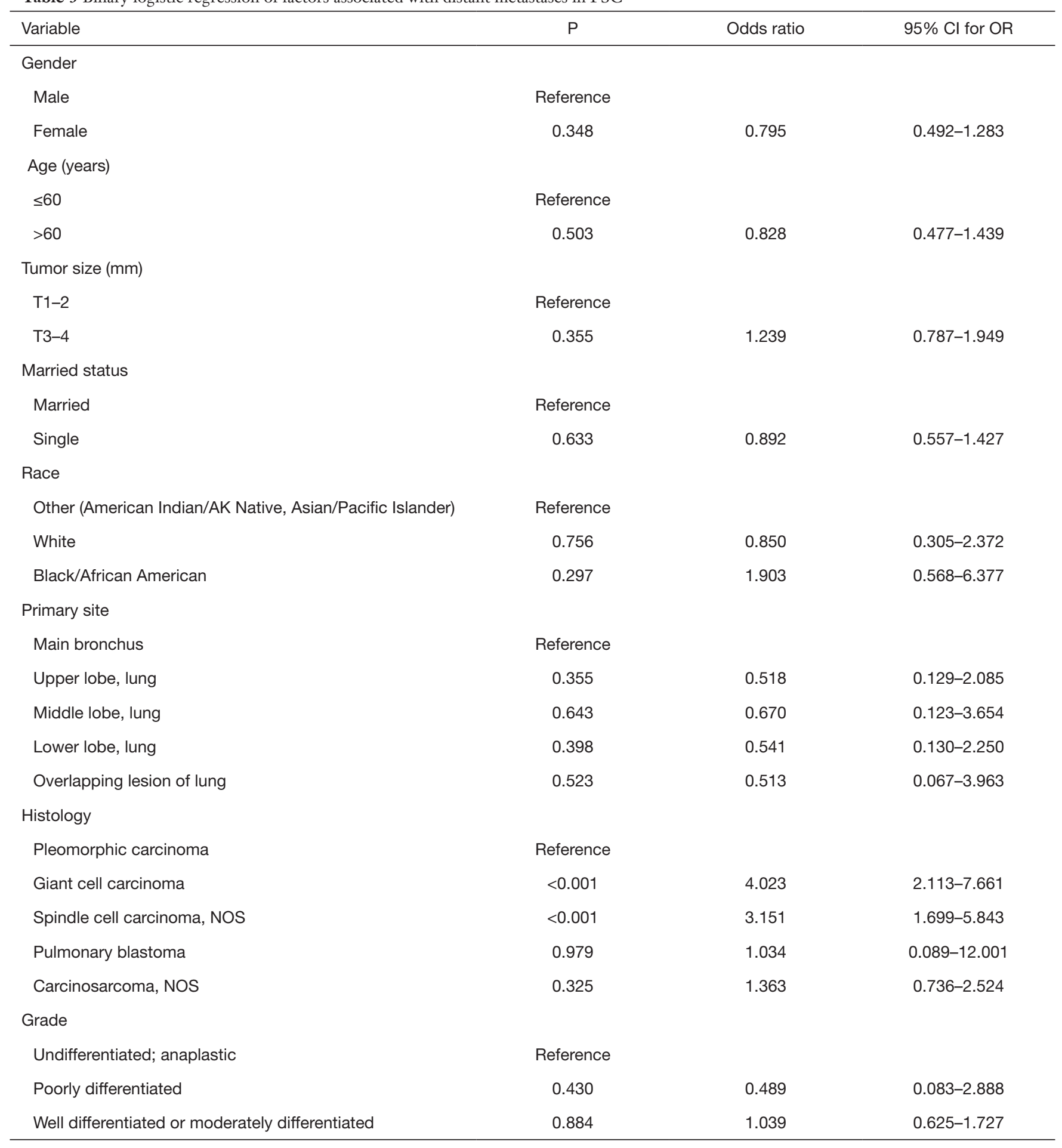

PSC, pulmonary sarcomatoid carcinoma. 
Table 4 1-y OS and median survival time of PSC patients

\begin{tabular}{lccc}
\hline Group & Number (\%) & 1-year OS (\%) & Median survival time (95 Cl) \\
\hline No metastasis & $422(45.2)$ & 58.2 & $19(13.879-24.121)$ \\
Metastasis & $512(54.8)$ & 14.1 & $2(1.633-2.367)$ \\
Single site & $192(20.6)$ & 12.1 & $3(2.373-3.627)$ \\
Multiple sites & $106(11.3)$ & 3.6 & $2(1.642-2.358)$ \\
Blank & $214(23.0)$ & - & - \\
\hline
\end{tabular}

PSC, pulmonary sarcomatoid carcinoma.
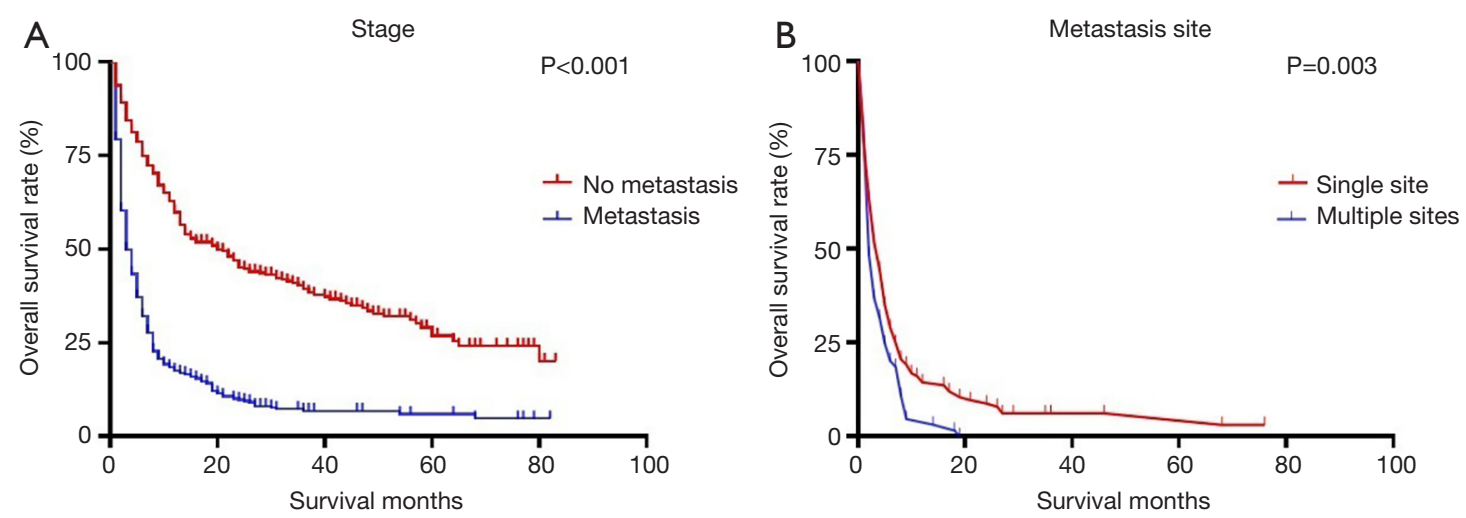

Figure 2 Kaplan-Meier overall survival curves for different metastasis states of PSC. PSC, pulmonary sarcomatoid carcinoma.

likely to associated with metastasis than patients with pleomorphic carcinoma. The 1-year OS rate and median survival time for PSC patients were summarized in Table 4. The survival curves of the non-metastases and metastases groups were analyzed using Kaplan-Meier plots. The 1-, 3-, and 5 -year OS rates in the non-metastases group (58.2\%, $38.3 \%$, and $26.1 \%$, respectively) were significantly higher $(\mathrm{P}<0.001)$ compared to that of the metastases group $(14.1 \%$, $5.5 \%$, and $4.8 \%$, respectively) (Figure 2). The 1-year OS rate and median time of single- and multi-site metastases showed statistical significance $(\mathrm{P}=0.003)$ (Figure 2).

Significant prognostic factors (age, primary site, grade, radiation and chemotherapy) of patients with single metastasis site identified in the univariate analysis were included as input variables for the Cox proportional hazard model. Multivariate analysis showed that patients aged $>60$ years of age (HR 1.874, 95\% CI: $1.018-3.450$, $\mathrm{P}=0.044)$ showed a worse prognosis whereas chemotherapy (HR 0.308, 95\% CI: 0.175-0.541, P<0.001) showed improved prognosis (Table 5). Survival curve with a significant log-rank $\mathrm{P}$ value $(\mathrm{P}<0.05)$ were depicted in Figure 3.

\section{Discussion}

Despite a high rate of distant PSC metastasis, the paucity of studies describing its clinicopathological characteristics necessitated a SEER-based analysis, which revealed factors related to metastasis and prognosis in patients with advanced metastasis in addition to clinical characteristics that may provide a reference for clinicians who are keen on developing personalized examination protocols.

Demographics of the study population showed that $80 \%$ of the PSC patients were white with an average age similar to that reported previously $(3,4,14)$. Our comparative analysis of non-metastasis and the metastasis groups showed an association between metastasis and large tumor size and spindle cell carcinoma, but there were no statistical differences in gender, age, primary site, grade, or marital status. In agreement with previous reports (5-7), we found a total distant metastatic rate of $54.8 \%$. However, the distant metastasis rates of different sites found in our study are novel findings that have not been reported previously.

The analysis of clinical characteristics of PSC metastatic site showed that compared to spindle cell carcinoma, pleomorphic and giant cell carcinomas were more likely 

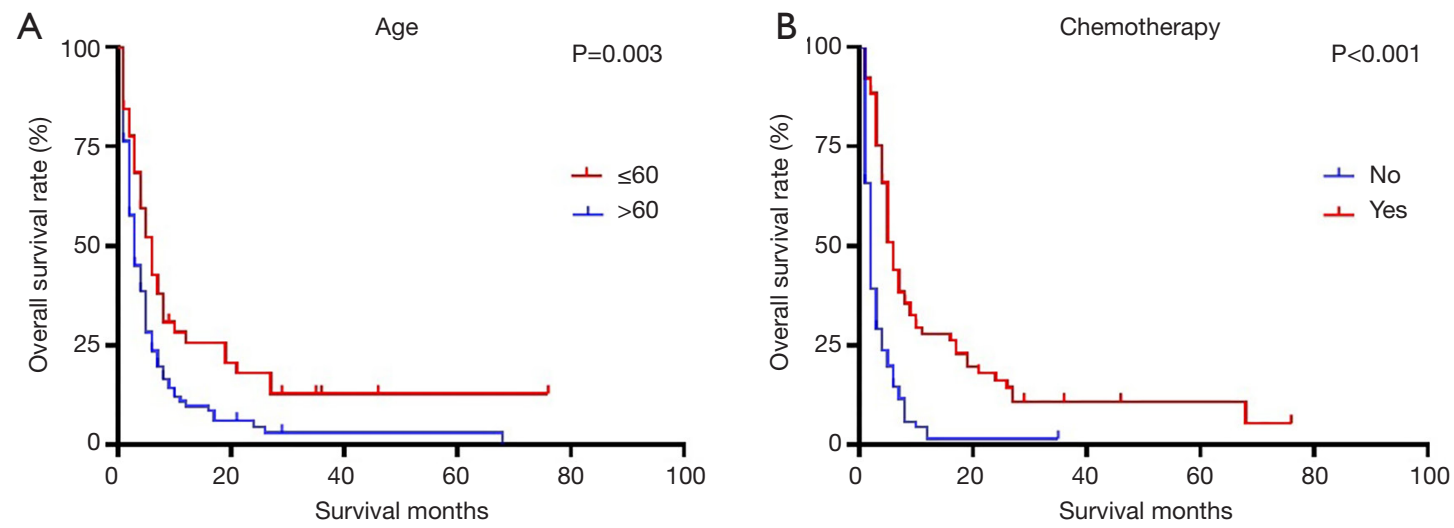

Figure 3 Survival curves demonstrating the effects of independent prognostic factors on the overall survival rate of PSC patients with single metastasis site. PSC, pulmonary sarcomatoid carcinoma.

Table 5 Survival analysis for PSC patients with single metastasis site

\begin{tabular}{|c|c|c|c|c|c|c|}
\hline Variable & \multicolumn{3}{|c|}{ Univariate analysis } & \multicolumn{3}{|c|}{ Multivariate analysis } \\
\hline \multicolumn{7}{|l|}{ Gender } \\
\hline Male & 2 & 10.4 & & - & - & - \\
\hline Female & 4 & 14.8 & 0.372 & - & - & - \\
\hline$\leq 60$ & 5 & 21.9 & & Reference & & \\
\hline$>60$ & 2 & 8.1 & 0.003 & 1.874 & $1.018-3.450$ & 0.044 \\
\hline \multicolumn{7}{|l|}{ Tumor size (mm) } \\
\hline $\mathrm{T} 1-\mathrm{T} 2$ & 3 & 13.2 & & - & - & - \\
\hline Married & 3 & 12.3 & & - & - & - \\
\hline Single & 2 & 13.4 & 0.652 & - & - & - \\
\hline \multicolumn{7}{|l|}{ Race } \\
\hline Other (American Indian/AK Native, Asian/Pacific Islander) & 3 & 12.7 & & - & - & - \\
\hline White & 3 & 11.6 & & - & - & - \\
\hline Black/African American & 4 & 15.2 & 0.572 & - & - & - \\
\hline \multicolumn{7}{|l|}{ Primary site } \\
\hline Main bronchus & 2 & 0 & & Reference & & \\
\hline
\end{tabular}

Table 5 (continued) 
Table 5 (continued)

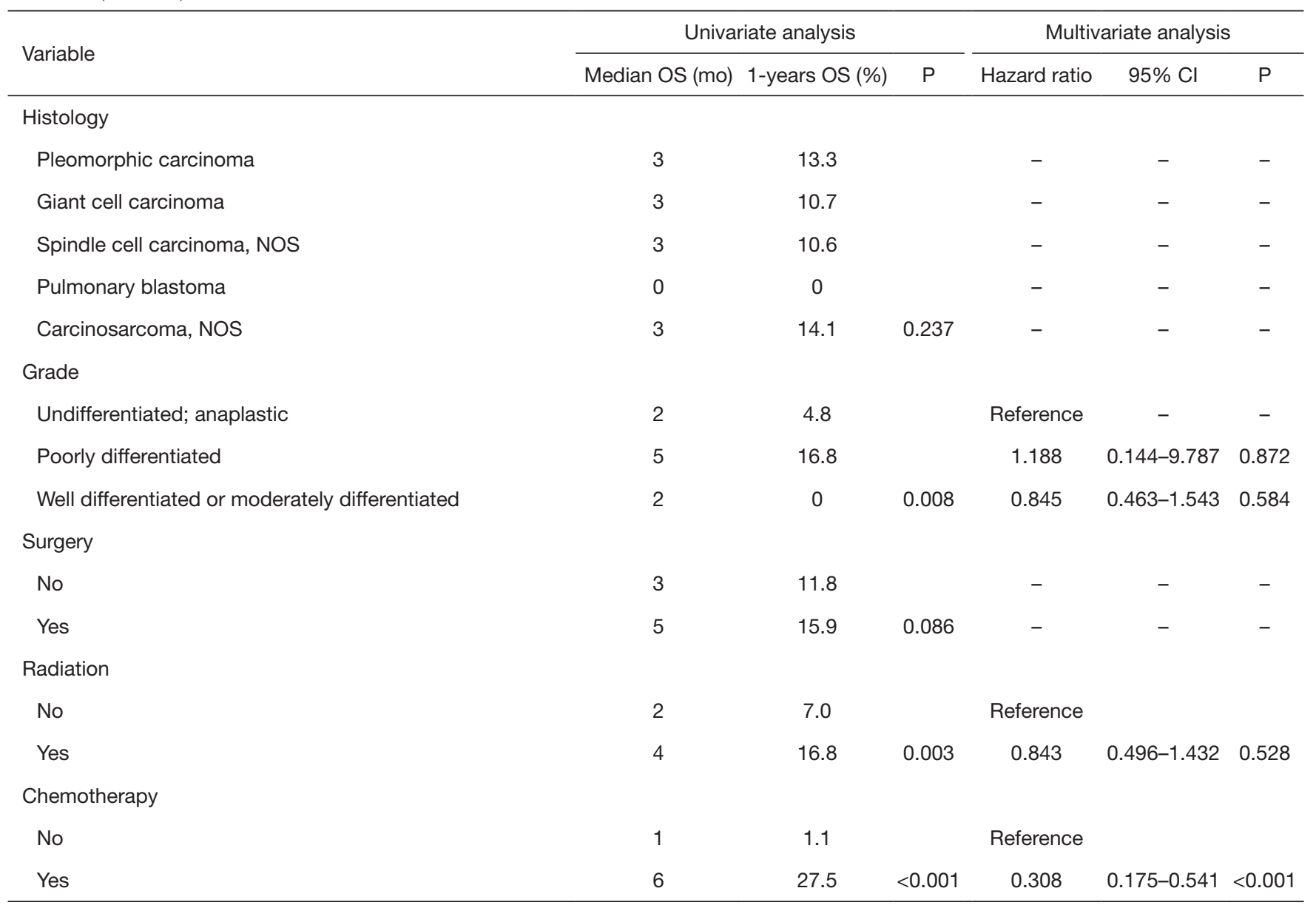

to be associated with brain metastasis. Besides, there was a higher proportion of patients younger than 60 years old with brain metastases in our study, suggesting that clinicians may consider more comprehensive brain tests for these clinical populations. Furthermore, binary logistic regression revealed that the occurrence of metastasis positively correlated with giant cell and spindle cell carcinomas, such that these carcinomas were potentially more metastatic than pleomorphic carcinomas. Therefore, our findings warrant a comprehensive metastasis-related image examination in these patients. Previous studies failed to capture a correlation between pathological types and metastasis due to the small sample sizes.

The 1-year OS log-rank test showed favorable prognosis of single metastasis site over multiple sites in PSC patients. Furthermore, the significantly lower survival rate of the metastases group compared to that of the non-metastases group is in concordance with rates reported in the literature
(5,15-17). As previously reported $(11,12)$, age was an independent prognostic factor in this study, older patients showed poor prognosis. We found that chemotherapy could significantly improve prognosis whereas radiotherapy did not, though a recent study showed that systemic chemotherapy alone did not improve survival of PSC patients (2). Further, despite an improved prognosis of metastatic PSC with chemotherapy, survival time remained short with a median survival time of only six months after chemotherapy, which may be associated with high rate of resistance to conventional first-line therapy (18). Though, tumor size, marital status, and histological type affected OS of PSC patients, as previously reported $(8,10,12,16,17,19)$, these factors did not significantly affect PSC patients with single-site metastasis. Together, these findings suggest that clinicians should consider chemotherapy for PSC patients with single metastasis site in the absence of other treatment options, despite short 
survival time after chemotherapy.

A comprehensive understanding of PSC along with rapid development of gene editing and immunotherapy in recent years, has opened several avenues for patients with advanced disease. While the SEER database lacked information on PSC related gene mutations, KRAS, $A L K, E G F R, M E T$, and $B R A F$ are common mutations in PSC reported previously (20-24). In addition, high PDL1 expression in some PSC patients has been reported $(25,26)$. As well, targeted therapy or immunotherapy has significantly improved prognosis of several cases $(23,24,27)$, and may become the mainstream treatment option for PSC patients in the future.

To the best of our knowledge, this is the first SEERbased study that focused on metastatic PSC patients. However, there are several limitations in this retrospective study that should be acknowledged. First, though the common metastatic sites included in the SEER database were the bone, brain, liver and lung, metastases in the heart $(28,29)$, duodenum (30), gingiva (31), and skin (32-34) have been reported, but not included in the SEER database, thereby underestimating the sample size in this study. Second, metastatic data retrieved from the SEER database were from 2010 to 2016, which may not provide sufficient follow-up time. Third, missing data on distant lymph node or other site metastases in SEER database precluded their inclusion in our analysis. We propose multicenter prospective studies in the future to overcome these limitations.

\section{Conclusions}

The SEER-based analysis revealed the clinical features of distant metastasis of PSC and showed that different histological types posed distinct metastasis potential. Besides, age and chemotherapy were the independent prognostic factors of PSC patients with single metastasis site.

\section{Acknowledgments}

The authors thank investigators and institutions involved in these studies and all patients whose data comprised the SEER Database.

Funding: This work was supported by the Natural Science Foundation of China (81602025), and 1.3.5 Project for Disciplines of Excellence and West China Hospital, Sichuan University (ZYGD18021).

\section{Footnote}

Reporting Checklist: The authors have completed the STROBE reporting checklist. Available at http://dx.doi. org/10.21037/jtd-20-2826

Peer Review File: Available at http://dx.doi.org/10.21037/jtd20-2826

Conflicts of Interest: All authors have completed the ICMJE uniform disclosure form (available at http://dx.doi. org/10.21037/jtd-20-2826). LXL serves as an unpaid editorial board member of Fournal of Thoracic Disease from Aug 2019-Jul 2021. The other authors have no conflicts of interest to declare.

Ethical Statement: The authors are accountable for all aspects of the work in ensuring that questions related to the accuracy or integrity of any part of the work are appropriately investigated and resolved. The study was conducted in accordance with the Declaration of Helsinki (as revised in 2013). This was an open database study that involved no identifiable information for individuals throughout the analysis, and therefore, Institutional Review Board of the Disciplines of Excellence and West China Hospital, Sichuan University (ZYGD18021) (1.3.5 Project) consent for this database analysis was waived.

Open Access Statement: This is an Open Access article distributed in accordance with the Creative Commons Attribution-NonCommercial-NoDerivs 4.0 International License (CC BY-NC-ND 4.0), which permits the noncommercial replication and distribution of the article with the strict proviso that no changes or edits are made and the original work is properly cited (including links to both the formal publication through the relevant DOI and the license). See: https://creativecommons.org/licenses/by-nc-nd/4.0/.

\section{References}

1. Siegel RL, Miller KD, Jemal A. Cancer statistics, 2019. CA Cancer J Clin 2019;69:7-34.

2. Karim NA, Schuster J, Eldessouki I, et al. Pulmonary sarcomatoid carcinoma: University of Cincinnati experience. Oncotarget 2018;9:4102-8.

3. Steuer CE, Behera M, Liu Y, et al. Pulmonary Sarcomatoid Carcinoma: An Analysis of the National Cancer Data Base. Clin Lung Cancer 2017;18:286-92. 
4. Yendamuri S, Caty L, Pine M, et al. Outcomes of sarcomatoid carcinoma of the lung: a Surveillance, Epidemiology, and End Results Database analysis. Surgery 2012;152:397-402.

5. Lococo F, Rapicetta C, Cardillo G, et al. Pathologic Findings and Long-Term Results After Surgical Treatment for Pulmonary Sarcomatoid Tumors: A Multicenter Analysis. Ann Thorac Surg 2017;103:1142-50.

6. Rahouma M, Kamel M, Narula N, et al. Pulmonary sarcomatoid carcinoma: an analysis of a rare cancer from the Surveillance, Epidemiology, and End Results database. Eur J Cardiothorac Surg 2018;53:828-34.

7. Ung M, Rouquette I, Filleron T, et al. Characteristics and Clinical Outcomes of Sarcomatoid Carcinoma of the Lung. Clin Lung Cancer 2016;17:391-7.

8. Maneenil K, Xue Z, Liu M, et al. Sarcomatoid Carcinoma of the Lung: The Mayo Clinic Experience in 127 Patients. Clin Lung Cancer 2018;19:e323-e33.

9. Travis WD, Brambilla E, Nicholson AG, et al. The 2015 World Health Organization Classification of Lung Tumors: Impact of Genetic, Clinical and Radiologic Advances Since the 2004 Classification. J Thorac Oncol 2015;10:1243-60.

10. Weissferdt A, Kalhor N, Correa AM, et al. "Sarcomatoid" carcinomas of the lung: a clinicopathological study of 86 cases with a new perspective on tumor classification. Hum Pathol 2017;63:14-26.

11. Roesel C, Terjung S, Weinreich G, et al. Sarcomatoid carcinoma of the lung: a rare histological subtype of non-small cell lung cancer with a poor prognosis even at earlier tumour stages. Interact Cardiovasc Thorac Surg 2017;24:407-13.

12. Liang X, Cheng Y, Yuan Z, et al. Clinical, pathological and treatment factors associated with the survival of patients with pulmonary sarcomatoid carcinoma. Oncol Lett 2020;19:4031-9.

13. Xu XL, Song W, Sui X, et al. Computed Tomographic and Pathological Features of Primary Pulmonary Sarcomatoid Carcinoma. Zhongguo Yi Xue Ke Xue Yuan Xue Bao 2016;38:93-8.

14. Ouziane I, Boutayeb S, Mrabti H, et al. Sarcomatoid carcinoma of the lung: a model of resistance of chemotherapy. N Am J Med Sci 2014;6:342-5.

15. Gu HT, Zhou JY, Wu T, et al. Clinical features and prognosis of pulmonary sarcomatoid carcinoma. Zhonghua Yi Xue Za Zhi 2018;98:744-8.

16. Huang SY, Shen SJ, Li XY. Pulmonary sarcomatoid carcinoma: a clinicopathologic study and prognostic analysis of 51 cases. World J Surg Oncol 2013;11:252.

17. Lin Y, Yang H, Cai Q, et al. Characteristics and Prognostic Analysis of 69 Patients With Pulmonary Sarcomatoid Carcinoma. Am J Clin Oncol 2016;39:215-22.

18. Vieira T, Girard N, Ung M, et al. Efficacy of first-line chemotherapy in patients with advanced lung sarcomatoid carcinoma. J Thorac Oncol 2013;8:1574-7.

19. Gu L, Xu Y, Chen Z, et al. Clinical analysis of 95 cases of pulmonary sarcomatoid carcinoma. Biomed Pharmacother 2015;76:134-40.

20. Jiang X, Liu Y, Chen C, et al. The value of biomarkers in patients with sarcomatoid carcinoma of the lung: molecular analysis of 33 cases. Clin Lung Cancer 2012;13:288-96.

21. Niu HT, Dong P, Wang JN, et al. Expression of anaplastic lymphoma kinase fusion gene in patients with lung sarcomatoid carcinoma and treatment analysis. Zhonghua Yi Xue Za Zhi 2018;98:688-91.

22. Yu Y, Zhang Q, Zhang J, et al. Prevalence of MET exon 14 skipping mutation in pulmonary sarcomatoid carcinoma patients without common targetable mutations: A singleinstitute study. J Cancer Res Ther 2019;15:909-13.

23. Schrock AB, Li SD, Frampton GM, et al. Pulmonary Sarcomatoid Carcinomas Commonly Harbor Either Potentially Targetable Genomic Alterations or High Tumor Mutational Burden as Observed by Comprehensive Genomic Profiling. J Thorac Oncol 2017;12:932-42.

24. Vieira T, Antoine M, Ruppert AM, et al. Blood vessel invasion is a major feature and a factor of poor prognosis in sarcomatoid carcinoma of the lung. Lung Cancer 2014;85:276-81.

25. Lococo F, Torricelli F, Rossi G, et al. Inter-relationship between PD-L1 expression and clinic-pathological features and driver gene mutations in pulmonary sarcomatoid carcinomas. Lung Cancer 2017;113:93-101.

26. Kim S, Kim MY, Koh J, et al. Programmed death-1 ligand 1 and 2 are highly expressed in pleomorphic carcinomas of the lung: Comparison of sarcomatous and carcinomatous areas. Eur J Cancer 2015;51:2698-707.

27. Salati M, Baldessari C, Calabrese F, et al. NivolumabInduced Impressive Response of Refractory Pulmonary Sarcomatoid Carcinoma with Brain Metastasis. Case Rep Oncol 2018;11:615-21.

28. Cote CL, Castonguay M, Baskett R. Resection of pulmonary sarcomatoid carcinoma metastasized to the right ventricle. J Card Surg 2020;35:1108-9.

29. Ng SW, Lim CH, Wang CW, et al. Primary pulmonary sarcomatoid carcinoma with intracardiac extension. Jpn J Thorac Cardiovasc Surg 2006;54:416-9. 
30. Jung LY, Jeon SY, Kim SR, et al. Pulmonary sarcomatoid carcinoma accompanying duodenal involvement. Am J Respir Crit Care Med 2012;185:899-900.

31. Qin Z, Huang B, Yu G, et al. Gingival metastasis of a mediastinal pulmonary sarcomatoid carcinoma: a case report. J Cardiothorac Surg 2019;14:161.

32. Tambe A, Ramadas P, Williams M, et al. Pulmonary sarcomatoid carcinoma presenting as subcutaneous

Cite this article as: Xiao C, Yang X, Hao J, Guo C, Pu Q, Liu L. Clinicopathological features and prognostic analysis of metastatic pulmonary sarcomatoid carcinoma: a SEER analysis. J Thorac Dis 2021;13(2):893-905. doi: 10.21037/jtd-20-2826 nodules. Proc (Bayl Univ Med Cent) 2020;33:67-8.

33. Yu J, Plaza JA, Schieke SM. Metastatic Sarcomatoid Lung Cancer: A Rare Cutaneous Spindle Cell Neoplasm. Am J Dermatopathol 2016;38:e36-e9.

34. Xu X, Lin M, Wang S, et al. Lung Sarcomatoid Carcinoma Metastasis to Skin: A Case Report and Review of the Literature. Cancer Invest 2016;34:286-92. 